\title{
How effective is family counselling on screen exposure of pre-school children?
}

\author{
Evin İlter Bahadur ${ }^{\oplus}$ Pınar Zengin Akkuş ${ }^{\oplus}$, Tuba Çelen Yoldaş ${ }^{\oplus}$ \\ Elif Nursel Özmert ${ }^{\oplus}$
}

Division of Developmental Pediatrics, Department of Pediatrics, Hacettepe University Faculty of Medicine, Ankara, Turkey.

\begin{abstract}
Background. Excessive screen viewing and background TV exposure are common problems all over the world. Therefore, intervention studies have gained importance. This study aims to investigate the effectiveness of family-based, developmental pediatrics clinic setting counseling in reducing screen time in typically developing children and to compare them with neurodevelopmental disorders.
\end{abstract}

Methods. Children (aged 24-62 months) who were exposed to screen viewing for at least 2 hours/day were included. Parents were given three counseling sessions to reduce excessive screen time. Parents reported daily screen time, co-viewing, background TV exposure, the duration of reading books and playing with their child.

Results. The study included 105 children (median age: 34 months IQR:28-41). Before counseling, the screen viewing time and the percentage of co-viewing among typically developing children $(\mathrm{n}=22)$ and children with a neurodevelopmental disorder $(n=83)$ were similar. There was a statistically significant decrease in screen time in both groups after the intervention. A higher impact was shown in the neurodevelopmental disorder group. The increase in percentages of co-viewing, as well as the increase in the time spent playing with their children, were statistically significant in the neurodevelopmental disorder group.

Conclusions. The study demonstrated that three pediatric office-setting counseling sessions including media use recommendations of the American Academy of Pediatrics are effective to decrease screen time for children who are either typically developing or with a neurodevelopmental disorder.

Key words: background TV exposure; excessive screen time; family counseling; neurodevelopmental disorder, pediatric office setting.

In recent years, children are being brought up in a digital world. Excessive screen time was found to be associated with various negative child health outcomes including language delay ${ }^{1}$, attention problems ${ }^{2}$, cognitive developmental delay. ${ }^{3}$ Since 2016 the American Academy of Pediatrics (AAP) has recommended no more than 1 hour per day of screen exposure for children aged 2-5 years. ${ }^{4}$ However, studies from

Evin İter Bahadur evinbahadur@gmail.com

Received 28th November 2019, revised 29th May 2020, accepted 24th June 2020.

This study was presented as oral presentation in the 62nd Turkish National Pediatric Congress 2018, Antalya, Turkey. various countries have shown that children's exposure to a screen is more than 2 hours per day. ${ }^{5,6}$ In the literature, there is conflicting evidence about screen-based activities of children with neurodevelopmental disorders (NDD). ${ }^{7-10}$

Not only screen viewing but also background TV exposure is associated with negative outcomes $^{11,12}$ Although not emphasized in studies related to screen intervention, background TV exposure is an important problem all over the world. A study in which low-income Mexican American parents were asked "How often their child was playing in the same room or near a TV that is on?" $43 \%$ of the parents reported that their child was often, 
very often and always doing so, in other words, exposed to background TV. ${ }^{13}$

Therefore, screen time intervention studies are important. The intervention studies showed that longer duration ( $>6$ months) and having high parent involvement, in studies in which the types of interventions were health promotion counseling, behavioral interventions and used electronic TV monitoring devices were effective strategies for reducing screen time. ${ }^{14,15}$ Preschool care setting, healthcare center/pediatric office setting interventions are less successful at reducing children's screen time than the other interventions. ${ }^{15}$ In the literature, only a limited number of intervention studies target reduction of screen time in pre-school children and the effects of interventions in reducing screen time are contradictory. ${ }^{15-17}$ Moreover, we could not reach any article in the published literature about the effectiveness of screen intervention in an office setting tackling background exposure beside screen viewing time and targeting both typically developing pre-school children and those with NDD.

The aim of this study was to evaluate the effectiveness of three consecutive family-based (high intensity) ${ }^{18}$, developmental pediatrics clinic setting counselling sessions, based on the media use recommendations of the American Academy of Pediatrics (AAP), in decreasing screen time, background TV exposure and in increasing development promoting activities of pre-school children with typically developing (TD) and NDD.

\section{Material and Methods}

This was a retrospective case control study conducted at Hacettepe University Ihsan Doğramacı Children's Hospital, Developmental Pediatrics Clinic. The study was approved by the Ethics Committee of Hacettepe University Faculty of Medicine on September 2018 (GO 18/317-27). The study also conforms to the provisions of the Declaration of Helsinki in 1995.

\section{Population}

Patients aged between 24-62 months admitted to the clinic between March 2014 - December 2017, who were exposed to screen viewing (using a computer, watching television or videos, mobile phone and playing video or computer game) for 2 hours or more whose parents were provided with counselling on three consecutive visits (high intensity) ${ }^{18}$ were included in the study.

Ages and Stages Questionnaire for Turkish children (ASQ-TR) ${ }^{19}$ and Bayley Scales of Infant and Toddler Development III ${ }^{20}$ with clinical observation were both used to evaluate the development level of children in the present study. Global developmental delay was defined as a delay in at least two developmental domains (communication, gross and fine motor skills, problem solving, and personal-social skills) in the standard development tests mentioned above. Autism Spectrum Disorder (ASD) was diagnosed via a clinical evaluation by a child psychiatrist and developmental pediatrician according to DSM-V criteria. Language development delay (LDD) was diagnosed based on a clinical evaluation by a developmental pediatrician and language speech therapist using one of the following scales; Bayley Scales of Infant and Toddler Development III, Preschool Language Scale Edition-5. ${ }^{21}$ Children admitted to the clinic due to parental concern regarding their development but who were considered as typically developing constituted the TD control group.

Feeding difficulty was defined as caregiver concern about child's feeding according to the study by Kerzner. ${ }^{22}$

\section{Study design}

During the first admission interview, information on the demographic data (age, gender, parental age, parental disease, parental education, mother's employment status, number of siblings), attending pre-school, feeding difficulties were all recorded. 
Screen time, background TV exposure, coviewing, promotion development activities, feeding difficulties were collected by a questionnaire specifically designed and asked for the study by the researchers. Screen time was measured using the question "how many hours is your child usually exposed to a screen (computer, television, mobile phones, etc) daily?". The background exposure was evaluated by asking parents "how many hours a day does your child usually spend next to a turned-on TV although he/she is not watching?". The percentage of co-viewing was measured by asking the parents "what is your daily percentage of watching the screen together?". The development promotion activities were asked by "how much did reading books and playing together changed after intervention?". Response options were no change, decrease, increase. Feeding difficulties were reported by the parents' answers to the question "do you have any concerns about your child's feeding?" If the caregiver answered yes, it was accepted that the child had a feeding difficulty.

\section{Intervention}

Screen timeinterventions are classified according to their intensity as low and high intensity. High intensity interventions are those having at least three interactions with family/child or the presence of an electronic monitoring device to limit screen time. ${ }^{18}$ The intervention in the study is high intensity as it included three consecutive counselling sessions in a developmental behavioral pediatric clinic. In each session, at least one parent received about 10-15 minutes behavioral counselling intervention face to face by a developmental pediatrician after the medical visit. The counselling included the AAP recommendations about screen viewing, information on the health and developmental effects of screen time on children, strategies to reduce screen time (reading books or playing together) and an explanation about the detrimental effects of background TV exposure.

\section{Statistical Analyses}

The statistical analysis was performed with IBM SPSS 22.0. Numerical variables were given as mean \pm standard deviation or median (interquartile ranges). Categorical variables were displayed as frequencies and percentages. Categorical variables were compared by chi square test. Normality of the continuous variables was evaluated by the Kolmogorov Smirnov test. Differences between the subgroups of NDD as they were not normally distributed according to continuous variables were determined by the Kruskal Wallis test. Differences between the TD and NDD groups according to daily median screen time and duration of playing together and reading books were determined by the Mann Whitney U test. Differences between the daily median screen time and median percentage of co-viewing before and after the intervention within each TD and NDD groups were determined by the Wilcoxon test. A p value of less than .05 was considered significant.

The power of the study, which included 105 children, was found to be $99 \%$ for screen duration and $81 \%$ for co-viewing with a $5 \%$ error rate.

\section{Results}

One hundred five children were included in the study, 83 with NDD and 22 TD pre-school aged children. The NDD group mainly comprised of children with three developmental disorders: Autism Spectrum Disorders (ASD) $(\mathrm{n}=24)$, Language Development Delay (LDD) $(n=34)$, Global Developmental Delay (GDD) ( $\mathrm{n}=25)$.

The demographic characteristics of the participants of the NDD and TD groups are shown in Table I. In the TD group, the mean age of children was $37.82 \pm 10.2$ months, $59 \%(n=13)$ were boys, $55 \%(n=11)$ of the mother's education level was less than 8 years and more than half of the mothers' $(n=13)$ were unemployed. In the 
NDD group, the mean age of children was 34.8 \pm 8.8 months, $68.6 \%(n=57)$ were boys, $51.2 \%$ $(n=41)$ of the mother's education level was less than 8 years and more than half of mothers' $(n=$ 59 ) were unemployed. There was no statistically significant difference between the groups except for the NDD mothers being younger than the TD mothers $(p=0.005)$ (Table I).

The mean duration between each counselling session was $4.1 \pm 1.2$ months.

The baseline median screen time before the intervention was 5.0 hours a day for all participants (Interquartile range (IQR): 4-9), after the intervention the median screen time for all participants decreased to 2.0 hours a day (IQR:1-3) $(\mathrm{p}<0.001)$. Before the intervention, the median percentage spent co-viewing was described as $12.5 \%$ of screen time, compared to $40 \%$ of screen time after the intervention $(\mathrm{p}=0.007)$ for all participants.

While background screen time was described as "whole day" in $89.8 \%(\mathrm{n}=89)$ of all participants $(\mathrm{n}=99)$ before the intervention, this decreased to $16.1 \%$ after the intervention. Before the intervention, parents of children in the TD and NDD groups reported that whole day

Table I. Comparison of the sociodemographic characteristics of children in the neurodevelopment disorder (NDD) and typically developing (TD) groups on admission.

\begin{tabular}{|c|c|c|c|}
\hline & $\mathrm{TD}(\mathrm{n}=22)$ & $\operatorname{NDD}(n=83)$ & P-value \\
\hline Age, month, mean \pm SD & $37.82 \pm 10.2$ & $34.8 \pm 8.8$ & 0.184 \\
\hline Gender (female/male) & $9 / 13$ & $26 / 57$ & 0.449 \\
\hline Maternal age, mean \pm SD & $35.19 \pm 4.99$ & $31.47 \pm 5.51$ & 0.005 \\
\hline Paternal age, mean \pm SD & $38.90 \pm 5.55$ & $36.58 \pm 6.42$ & 0.107 \\
\hline Maternal education, N (\%) & & & 0.807 \\
\hline$\leq 8$ year & $11(55.0)$ & $41(51.2)$ & \\
\hline 9-12 year & $3(15.0)$ & $22(27.5)$ & \\
\hline$>12$ year & $6(30.0)$ & $17(21.3)$ & \\
\hline Paternal education, N (\%) & & & 0.186 \\
\hline$\leq 8$ year & $9(50)$ & $27(33.8)$ & \\
\hline 9-12 year & $6(33.3)$ & $31(38.8)$ & \\
\hline$>12$ year & $3(16.7)$ & $22(27.5)$ & \\
\hline Maternal employment, N (\%) & & & 0.463 \\
\hline Employed & $4(23.5)$ & $10(14.5)$ & \\
\hline Unemployed & $13(76.5)$ & $59(85.5)$ & \\
\hline No. of sibling, N (\%) & & & 0.717 \\
\hline None & $6(27.3)$ & $25(30.5)$ & \\
\hline One sibling & $9(40.9)$ & $38(46.3)$ & \\
\hline Two or more sibling & $7(31.8)$ & $19(23.2)$ & \\
\hline Attending to preschool education N (\%) & & & 0.603 \\
\hline Yes & $2(9.1)$ & $4(4.8)$ & \\
\hline No & $20(90.9)$ & $79(95.2)$ & \\
\hline Feeding difficulties, N (\%) & & & 0.809 \\
\hline Yes & $12(54.5)$ & $49(59)$ & \\
\hline No & $10(45.5)$ & $34(41)$ & \\
\hline Parental disease, N (\%) & & & 0.591 \\
\hline Yes & $7(31.8)$ & $21(25.3)$ & \\
\hline No & $15(68.2)$ & $62(74.7)$ & \\
\hline
\end{tabular}


background TV exposure was $72.7 \%(\mathrm{n}=16)$ and $92.8 \%(\mathrm{n}=77)$ respectively. After the intervention, these percentages decreased to $16.7 \%(n=3 / 18)$ and $16.3 \%(n=13 / 80)$ of children respectively.

Before the intervention only, the median screen time was statistically significantly different in families indicating a feeding difficulty (Table II).

At the beginning of the study only 6 children were attending preschool. After the intervention, 49 children started attending preschool. However, no difference was found for these children either at the baseline or at the end of 3 visits compared to those not attending preschool for the median duration of screen viewing (5.0 $[\mathrm{IQR}=4.0-8.0], 5.0[\mathrm{IQR}=4.0-10.0] ; 2.0[\mathrm{IQR}=$ 1.0 - 3.6], 2.0 [IQR=1.0 - 3.0]), respectively. After the intervention the only statistically significant demographic characteristic for longer screen time was found as NDD (Table II).

The screen viewing characteristics of the TD and NDD children before and after the intervention are displayed in Table III. The median baseline viewing durations of TD and NDD groups were 5.5 hrs. (IQR: 3.75-10.0), 5.0 hrs. (IQR=4.0-8.0), respectively $(p=0.820)$. After the intervention the median viewing durations of TD and NDD groups were $3.0 \mathrm{hrs}$. (IQR:2.0-3.62), 2.0 hrs. (IQR=1.0-3.0), respectively, $(\mathrm{p}=0.039)$. The intervention decreased screen viewing time in both groups with statistical significance, however, the decrease was much greater in the NDD group children. The percentages of families in the NDD and TD groups reporting an increase in reading books after the intervention were $45.3 \%$ and $47.1 \%$ respectively. An increase of $78.5 \%$ in time spent playing with their child for the NDD group whereas this increase was $44.4 \%$ for the TD group. ( $\mathrm{p}=0.008)$ (Table III).

\section{Discussion}

The study focused on decreasing background TV exposure besides screen viewing time and increasing the duration of household development promotion activities (reading books, playing with their child) after three consecutive counselling sessions to parents of pre-school children with NDD and TD in a developing country. The counselling sessions, which took place in a developmental behavioral pediatric clinic, were based on AAP media use recommendations. This intervention was effective in reducing the total screen time and background television exposure in both NDD and TD children.

Before the intervention, only children having a feeding difficulty were found to have higher screen time. This finding is consistent with the literature. The previous studies showed that TV exposure was associated with disordered eating and insufficient consumption of vegetables and fruits. ${ }^{23,24}$ Longer background TV exposure was associated with opening the TV during meal times. ${ }^{13}$ According to previous studies low household income, lower parental education and female gender were associated with highscreen time. ${ }^{25,26}$ Parental education, gender, age, occupations of parents were not associated with high screen time in this study.

The screen viewing time and the percentage of co-viewing before counselling were similar among typically developing children and children with neurodevelopmental disorder. The study by Montes ${ }^{12}$ recorded no difference for screen viewing time between children with ASD and children without ASD. In this study, it was demonstrated that not only children with ASD but also a group of children with NDD had similar screen viewing duration to TD children.

The majority of the parents in both NDD and TD groups reported "whole day" background TV exposure before the intervention. Our observation likewise that in Thompson's study $^{13}$, is that most parents did not know the detrimental effects of background exposure.

After the intervention, there was also a statistically significant decrease in screen time and background TV exposure in both groups. In this study, a higher impact was shown in the neurodevelopmental disorder group. Montes ${ }^{10}$ 
Table II. Screen time covariates before and after intervention for all participants.

\begin{tabular}{|c|c|c|}
\hline & Before intervention ( $\mathrm{n}=105)$ & After intervention ( $\mathrm{n}=105)$ \\
\hline & Daily Median Screen Time-hour (IQR) & Daily Median Screen Time-hour (IQR) \\
\hline Gender & & \\
\hline Male $(n=70)$ & $5.0(4.0-7.25)$ & $2.0(1.0-3.0)$ \\
\hline Female $(n=35)$ & $6.0(4.0-10.0)$ & $2.0(1.0-3.0)$ \\
\hline Maternal age & & \\
\hline$\leq 35$ y $(n=64)$ & $5.0(4.0-10.0)$ & $2.0(1.0-3.0)$ \\
\hline$>35$ y $(n=38)$ & $5.5(4.0-7.25)$ & $2.0(1.0-3.0)$ \\
\hline Paternal age & & \\
\hline$\leq 35$ y $(n=36)$ & $5.5(4.0-10.0)$ & $2.0(1.12-3.37)$ \\
\hline$>35$ y $(n=65)$ & $5.0(4.0-7.5)$ & $2.0(1.0-3.0)$ \\
\hline Maternal education & & \\
\hline$<8$ years $(n=52)$ & $6.0(4.0-9.5)$ & $2.0(1.0-3.0)$ \\
\hline $9-12$ year $(n=25)$ & $5.0(4.0-10.0)$ & $2.0(1.0-3.5)$ \\
\hline$>12$ year $(n=23)$ & $5.0(4.0-12.0)$ & $2.0(2.0-3.0)$ \\
\hline Paternal education & & \\
\hline$<8$ year $(\mathrm{n}=36)$ & $6.0(4.0-10)$ & $2.5(0.62-3.75)$ \\
\hline $9-12$ year $(n=37)$ & $5.0(4.0-9.0)$ & $2.0(1.0-3.0)$ \\
\hline$>12$ year $(n=25)$ & $5.0(4.0-7.0)$ & $2.0(1.0-3.0)$ \\
\hline Maternal employment & & \\
\hline Employed (n=14) & $4.5(3.75-12.0)$ & $2.0(1.0-3.0)$ \\
\hline Unemployed ( $\mathrm{n}=72)$ & $5.0(4.0-10.0)$ & $2.0(1.0-3.0)$ \\
\hline No.of sibling & & \\
\hline None $(n=20)$ & $5.5(4.0-10.0)$ & $2.0(1.0-3.0)$ \\
\hline one sibling $(\mathrm{n}=37)$ & $5.0(4.0-10.0)$ & $2.0(1.0-3.0)$ \\
\hline two or more sibling $(\mathrm{n}=17)$ & $4.0(3.5-6.5)$ & $2.0(1.75-3.0)$ \\
\hline Feeding difficulties* & & \\
\hline No $(n=61)$ & $5.0(4.0-6.0)^{*}$ & $2.0(1.0-3.0)$ \\
\hline Yes $(n=44)$ & $6.0(4.0-11.5)^{*}$ & $2.0(1.1-3.0)$ \\
\hline Parental disease & & \\
\hline No $(n=77)$ & $5.0(4.0-10.0)$ & $2.0(1.0-3.0)$ \\
\hline Yes $(n=28)$ & $5.0(4.0-7.5)$ & $2.0(1.0-3.0)$ \\
\hline Developmental status ${ }^{* *}$ & & \\
\hline Typically developing $(\mathrm{n}=22)$ & $5.5(3.75-10.0)$ & $3.0(2.0-3.62)^{* *}$ \\
\hline $\begin{array}{l}\text { Neurodevelopmental disorder } \\
(\mathrm{n}=83)\end{array}$ & $5.0(4.0-8.0)$ & $2.0(1.0-3.0)^{* *}$ \\
\hline
\end{tabular}

${ }^{*} \mathrm{p}<0.05$ before intervention

${ }^{* *} \mathrm{p}<0.05$ after intervention

no differences to determine for other comparison

IQR: Interquartile range

recommends that pediatricians should take into account the fact that children with ASD and their families are quite similar to families of children without ASD with regard to the use of screens so the same recommendations should be given to the parents of both groups. This study demonstrated that the same intervention could be effective in reducing total screen time of all of the NDD groups and TD children statistically significantly as suggested by Montes. 
Table III. Screen viewing characteristics of typically developing children (TD) and children with neurodevelopmental disorder [NDD- Autism Spectrum Disorder (ASD), Language Development Delay (LDD), Global Development Delay (GDD)] before and after intervention.

\begin{tabular}{lccccc}
\hline & TD & NDD TOTAL & ASD & LDD & GDD \\
\hline $\begin{array}{l}\text { Daily Median Screen Time } \\
\text { hour (IQR) }\end{array}$ & $\mathrm{n}=22$ & $\mathrm{n}=83$ & $\mathrm{n}=24$ & $\mathrm{n}=34$ & $\mathrm{n}=25$ \\
$\quad \begin{array}{l}\text { Before intervention } \\
\text { After intervention }\end{array}$ & $5.5^{\mathrm{a}}(3.75-10.0)$ & $5.0^{\mathrm{a}}(4.0-8.0)$ & $6.0(4.0-11.5)$ & $4.5(4.0-6.0)$ & $6.0(4.0-10.0)$ \\
$\mathrm{p}^{*}$ value & $3.0^{\mathrm{bc}}(2.0-3.62)$ & $2.0^{\mathrm{b}}(1.0-3.0)$ & $1.0^{\mathrm{cd}}(0.5-2.0)$ & $2.0(1.0-3.0)$ & $2.0^{\mathrm{bd}}(2.0-4.0)$ \\
& $<0.01$ & $<0.01$ & $<0.01$ & $<0.01$ & $<0.01$
\end{tabular}

Median Percentage of Co-viewing

(\%) (IQR)

$\begin{array}{lccccc}\text { Before intervention } & 0.0(0-32.50) & 20.0(0.0-50.0) & 22.5(0-50) & 12.5(0-50) & 20.0(0-50) \\ \text { After intervention } & 25.0(0-80.0) & 40.0(0.0-70.0) & 50.0(5-100) & 22.5(0-65) & 50.0(10-70) \\ \mathrm{p}^{*} \text { value } & 0.117 & 0.022 & 0.097 & 0.393 & 0.125\end{array}$

Families reporting increase Reading Book

After Intervention $\mathrm{n}(\%)$

$\begin{array}{llllll}\text { no change } & 9(52.9) & 35(54.7) & 12(54.5) & 13(54.2) & 10(55.6) \\ \text { increase } & 8(47.1) & 45(45.3) & 10(45.5) & 11(45.8) & 8(44.4)\end{array}$

Families reporting increase Playing Together

After Intervention $\mathrm{n}(\%)$

\begin{tabular}{lccccc} 
no change & $10(55.6)$ & $14(21.5)$ & $6(27.3)$ & $6(22.2)$ & $2(12.5)$ \\
increase & $8(44.4)^{\mathrm{ef}}$ & $51(78.5)^{\mathrm{f}}$ & $16(72.7)^{\mathrm{e}}$ & $21(77.8)^{\mathrm{e}}$ & $14(87.5)^{\mathrm{e}}$ \\
\hline
\end{tabular}

$\mathrm{p}^{*}$ dependent sample Wilcoxon tests were used for before and after intervention in each group,

a: $\mathrm{p}=.820$ independent samples Mann-Whitney test were used

b: $p=.039$ independent samples Mann-Whitney test were used

c: $\mathrm{p}=.002$ independent samples Kruskal- Wallis test were used

$\mathrm{d}: \mathrm{p}=.004$ independent samples Kruskal- Wallis test were used

e: $p=.034$ independent samples Kruskal wallis test were used

$\mathrm{f}: \mathrm{p}=.008$ independent samples Mann-Whitney test were used

no differences to determine for other comparison

While in the literature office setting interventions were found to be less successful than others ${ }^{15}$, office setting interventions are preferred by health professionals because these interventions require less time and have more applicability than home, community and primary care settings. The study by Birken et al. ${ }^{16}$ which made only one brief behavioral counseling intervention to pre-school children in a pediatric office setting showed no effect of the intervention on overall screen time. Our study differed from this by giving three consecutive interventions, which have shown to be effective, and by lasting for more than one year. In the study by Downing et al. ${ }^{15}$ it was also recommended that an effective intervention study should last for more than a 6-month period. The other two office setting intervention studies were associated with diet, physical activities and reducing screen time during well child visits. Overweight and obese children were included to these studies. The study by Taveras et al. $^{27}$ showed that intervention participants who completed at least 2 intervention activities had a greater decrease in the duration of TV and video viewing. A study by van Grieken et al. ${ }^{28}$ was a low intensity obesity intervention, which focused only on TV viewing, showed no difference between the intervention and control group TV viewing. This study differed from the other two by focusing mainly on screen viewing time, while promoting book reading, play in NDD children, and succeeded in reducing total screen time in this population significantly. 
The effectiveness of the intervention which was conducted in a developmental behavioral pediatric clinic, may also be related to the increased awareness of the families about the detrimental effects of screen viewing on developmental delay, on language and communication fields as well as behavioral problems. Therefore, as recommended in the review by Downing et al. ${ }^{15}$ it is important to design the intervention to be family-based in order to be successful. The family plays the primary role in the social environment and the behavioral development of the child. ${ }^{29}$ Limiting screen time and active role model behavior are key factors that prevent excessive time spent on screen-based behavior. ${ }^{29}$ Therefore, families who took part in the study were asked to limit the screen time and become role models for screen-based behavior.

As mentioned above, repeating counselling and extending it for more than one year were another reason for effectiveness.

It is worth pointing out that the reliance on parental reports for children's screen-based habits may be a limitation of the current study. However, parent- reported screen time was used in many previous studies ${ }^{17,30}$ and a high correlation was found between parent-reported screen time and screen time of children. ${ }^{31}$ Screen time was not evaluated after each counselling but only after the three sessions as previous studies recommend and consider as an effective high intensity intervention. The small sample size is another limitation of the study.

Limiting screen time has been recommended by the AAP for more than a decade, but there has been limited success in reducing children's screen time. This study reveals the use and effectiveness of a developmental pediatrics clinic setting intervention via parents, across three sessions including the AAP media recommendations in NDD children, which are applicable, accessible and cost-effective. There is an apparent need for larger sample group studies among children with NDD. Further research is necessary to define the long-lasting effects of such an intervention.

\section{REFERENCES}

1. Christakis DA, Gilkerson J, Richards JA, et al. Audible television and decreased adult words, infant vocalizations, and conversational turns: a population-based study. Arch Pediatr Adolesc Med 2009; 163: 554-558.

2. Jolin EM, Weller RA. Television viewing and its impact on childhood behaviors. Curr Psychiatry Rep 2011; 13: 122-128.

3. Carson V, Kuzik N, Hunter S, et al. Systematic review of sedentary behavior and cognitive development in early childhood. Prev Med 2015; 78: 115-122.

4. Council on Communications and Media. Media and young minds. Pediatrics 2016; 138: e20162591.

5. Jari M, Qorbani M, Motlagh ME, Heshmat R, Ardalan G, Kelishadi R. A nationwide survey on the daily screen time of Iranian children and adolescents: the CASPIAN-IV study. Int J Prev Med 2014; 5: 224-229.

6. Zhao J, Zhang Y, Jiang F, et al. Excessive screen time and psychosocial well-being: the mediating role of body mass index, sleep duration, and parent-child interaction. J Pediatr 2018; 202: 157-162. e1.

7. Chonchaiya W, Nuntnarumit P, Pruksananonda C. Comparison of television viewing between children with autism spectrum disorder and controls. Acta Paediatr 2011; 100: 1033-1037.

8. Mazurek MO, Wenstrup C. Television, video game and social media use among children with ASD and typically developing siblings. J Autism Dev Disord 2013; 43: 1258-1271.

9. Nally B, Houlton B, Ralph S. Researches in brief: the management of television and video by parents of children with autism. Autism 2000; 4: 331-337.

10. Montes G. Children with autism spectrum disorder and screen time: results from a large, nationally representative US study. Acad Pediatr 2016; 16: 122128.

11. Linebarger DL, Barr R, Lapierre MA, Piotrowski JT. Associations between parenting, media use, cumulative risk, and children's executive functioning. J Dev Behav Pediatr 2014; 35: 367-377.

12. Hudon TM, Fennell CT, Hoftyzer M. Quality not quantity of television viewing is associated with bilingual toddlers' vocabulary scores. Infant Behav Dev 2013; 36: 245-254.

13. Thompson DA, Tschann JM. Factors contributing to background television exposure in low-income Mexican-American preschoolers. Matern Child Health J 2016; 20: 1835-1841. 
14. Wu L, Sun S, He Y, Jiang B. The effect of interventions targeting screen time reduction: a systematic review and meta-analysis. Medicine (Baltimore) 2016; 95: e4029.

15. Downing KL, Hnatiuk JA, Hinkley T, Salmon J, Hesketh KD. Interventions to reduce sedentary behaviour in 0-5-year-olds: a systematic review and meta-analysis of randomised controlled trials. Br J Sports Med 2018; 52: 314-321.

16. Birken CS, Maguire J, Mekky M, et al. Office-based randomized controlled trial to reduce screen time in preschool children. Pediatrics 2012; 130: 1110-1115.

17. Dennison BA, Russo TJ, Burdick PA, Jenkins PL. An intervention to reduce television viewing by preschool children. Arch Pediatr Adolesc Med 2004; 158: 170-176.

18. Community Preventive Services Task Force. Reducing children's recreational sedentary screen time: recommendation of the Community Preventive Services Task Force. Am J Prev Med 2016; 50: 416418.

19. Kapci EG, Kucuker S, Uslu RI. How applicable are ages and stages questionnaires for use with Turkish children? Topics Early Child Spec Educ 2010; 30: 176-188.

20. Bayley N. Bayley Scales of Infant and Toddler Development. San Antonio: Psychological Corporation, 2006.

21. Sahli AS, Belgin E. Adaptation, validity, and reliability of the Preschool Language Scale-Fifth Edition (PLS-5) in the Turkish context: the Turkish Preschool Language Scale-5 (TPLS-5). Int J Pediatr Otorhinolaryngol 2017; 98: 143-149.

22. Kerzner B, Milano K, MacLean WC Jr, Berall G, Stuart S, Chatoor I. A practical approach to classifying and managing feeding difficulties. Pediatrics 2015; 135: 344-353.

23. Moriarty CM, Harrison K. Television exposure and disordered eating among children: a longitudinal panel study. J Commun 2008; 58: 361-381.
24. Utter J, Scragg R, Schaaf D. Associations between television viewing and consumption of commonly advertised foods among New Zealand children and young adolescents. Public Health Nutr 2006; 9: 606612.

25. Anand S, Krosnick JA. Demographic predictors of media use among infants, toddlers, and preschoolers. Am Behav Sci 2005; 48: 539-561.

26. Andersen RE, Crespo CJ, Bartlett SJ, Cheskin LJ, Pratt M. Relationship of physical activity and television watching with body weight and level of fatness among children: results from the Third National Health and Nutrition Examination Survey. JAMA 1998; 279: 938-942.

27. Taveras EM, Gortmaker SL, Hohman $\mathrm{KH}$, et al. Randomized controlled trial to improve primary care to prevent and manage childhood obesity: the High Five for Kids study. Arch Pediatr Adolesc Med 2011; 165: 714-722.

28. van Grieken A, Renders CM, Veldhuis L, Looman CW, Hirasing RA, Raat H. Promotion of a healthy lifestyle among 5-year-old overweight children: health behavior outcomes of the 'Be active, eat right'study. BMC Public Health 2014; 14: 59.

29. Veitch J, Arundell L, Hume C, Ball K. Children's perceptions of the factors helping them to be 'resilient'to sedentary lifestyles. Health Educ Res 2013; 28: 692-703.

30. Robinson TN, Wilde ML, Navracruz LC, Haydel KF, Varady A. Effects of reducing children's television and video game use on aggressive behavior: a randomized controlled trial. Arch Pediatr Adolesc Med 2001; 155: 17-23.

31. Anderson DR, Field DE, Collins PA, Lorch EP, Nathan JG. Estimates of young children's time with television: a methodological comparison of parent reports with time-lapse video home observation. Child Dev 1985: 56: 1345-1357. 